\title{
Using the Landsat Burned Area Products to Derive Fire History Relevant for Fire Management and Conservation in the State of Florida, Southeastern USA ${ }^{\dagger}$
}

\author{
Casey Teske $^{1, *}$, Melanie K. Vanderhoof ${ }^{2}{ }^{(0)}$, Todd J. Hawbaker ${ }^{2}{ }^{\mathbb{D}}$, Joe Noble ${ }^{3}$ and John Kevin Hiers ${ }^{3}$ \\ 1 U.S. Fish and Wildlife Service, Branch of Fire Management, 3833 S Development Ave., Boise, ID 83705, USA \\ 2 U.S. Geological Survey, Geosciences and Environmental Change Science Center, Denver Federal Center, P.O. \\ Box 25046, MS 980, Denver, CO 80225, USA; mvanderhoof@usgs.gov (M.K.V.); tjhawbaker@usgs.gov (T.J.H.) \\ 3 Tall Timbers Research Station, 13093 Henry Beadel Dr., Tallahassee, FL 32312, USA; jnoble@ttrs.com (J.N.); \\ jkhiers@ttrs.com (J.K.H.) \\ * Correspondence: casey_teske@fws.gov; Tel.: +1-208-387-5831 \\ + This work was authored as part of the Contributor's official duties as an Employee of the United States \\ Government and is therefore a work of the United States Government. In accordance with 17 U.S.C. 105, no \\ copyright protection is available for such works under U.S. Law. This is an Open Access article that has been \\ identified as being free of known restrictions under copyright law, including all related and neighboring \\ rights (https:// creativecommons.org/publicdomain/mark/1.0/, accessed on 1 February 2021). You can copy, \\ modify, distribute, and perform the work, even for commercial purposes, all without asking permission.
}

Citation: Teske, C.; Vanderhoof, M.K.; Hawbaker, T.J.; Noble, J.; Hiers, J.K. Using the Landsat Burned Area Products to Derive Fire History Relevant for Fire Management and Conservation in the State of Florida Southeastern USA . Fire 2021, 4, 26. https://doi.org/10.3390/fire4020026

Academic Editor: Alistair M. S. Smith

Received: 21 March 2021

Accepted: 5 May 2021

Published: 8 May 2021

Publisher's Note: MDPI stays neutral with regard to jurisdictional claims in published maps and institutional affiliations.

Copyright: (c) 2021 by the authors Licensee MDPI, Basel, Switzerland. This article is an open access article distributed under the terms and conditions of the Creative Commons Attribution (CC BY) license (https:// creativecommons.org/licenses/by/ $4.0 /)$.
Abstract: Development of comprehensive spatially explicit fire occurrence data remains one of the most critical needs for fire managers globally, and especially for conservation across the southeastern United States. Not only are many endangered species and ecosystems in that region reliant on frequent fire, but fire risk analysis, prescribed fire planning, and fire behavior modeling are sensitive to fire history due to the long growing season and high vegetation productivity. Spatial data that map burned areas over time provide critical information for evaluating management successes. However, existing fire data have undocumented shortcomings that limit their use when detailing the effectiveness of fire management at state and regional scales. Here, we assessed information in existing fire datasets for Florida and the Landsat Burned Area products based on input from the fire management community. We considered the potential of different datasets to track the spatial extents of fires and derive fire history metrics (e.g., time since last burn, fire frequency, and seasonality). We found that burned areas generated by applying a $90 \%$ threshold to the Landsat burn probability product matched patterns recorded and observed by fire managers at three pilot areas. We then created fire history metrics for the entire state from the modified Landsat Burned Area product. Finally, to show their potential application for conservation management, we compared fire history metrics across ownerships for natural pinelands, where prescribed fire is frequently applied. Implications of this effort include increased awareness around conservation and fire management planning efforts and an extension of derivative products regionally or globally.

Keywords: burned area; prescribed fire; fire metrics; fire history; fire regime; fire management; conservation

\section{Introduction}

The use of prescribed fire as a management and conservation tool has a long and varied history. In addition to using prescribed fire as a tool to protect life and property, the use of prescribed fire to enhance ecosystem services and increase biological conservation efforts is recognized and reflected in current literature (see [1-4]) and policies [5] and implemented in present-day management practices [6-8]. Although these issues are widespread, a contemporary example of intertwining biological conservation efforts, ecosystem services, and protection of values at risk exists in the southeastern United States. 
Prescribed fire spatial data quality and availability vary significantly across the US; most reported burned area represents incomplete estimates from a variety of sources. Nonetheless, by all estimates, the southeast (SE) outpaces the rest of the United States in the amount of prescribed fire applied annually to the landscape [4,9]. In the 13 SE states, a 2011 survey of state forestry agencies showed that more than $24,000 \mathrm{~km}^{2}$ of private and public land were burned annually with prescribed fire for forestry-based objectives [10]. In 2014, the extent of prescribed burning in the SE states accounted for nearly $68 \%$ of the national total [11,12]. Nowell et al. [13] documented the total area burned by wildfires in Florida to be $10 \%$ of that burned by prescribed fires, suggesting that the high amount of intentional burning in the SE reduces wildfire size and occurrence [14]. In Florida alone, nearly 70\% of the state is in private land ownership [15], and most prescribed fire authorizations (i.e., permits) are for private lands both in terms of numbers of authorizations and area burned [13].

The use of prescribed fire on private lands for forestry and conservation objectives is important in the SE, although agricultural burning is also prominent. One of the many reasons for using prescribed fire in the $\mathrm{SE}$ is to maintain habitat conditions for the numerous ecosystems and species that depend on fire [16,17]. For example, longleaf pine (Pinus palustris Mill.) is a foundation fire-dependent tree species occurring in the SE that requires frequent, low-intensity surface fires $[1,18]$. The health of longleaf pine ecosystems is paramount for many of the species dependent on it, including gopher tortoises, indigo snakes, and red cockaded woodpeckers. Metrics such as fire seasonality and time since last burn are important components in assessing the condition of these fire-maintained systems $[1,19,20]$. For many species that are dependent on these systems, managing an appropriate fire return interval is critical $[16,17,21,22]$. This is especially important in areas similar to the SE United States, where much of the lands are under private ownership, and keeping spatially explicit fire records is not required by law.

Cost-effective and efficient management of our natural resources requires up-to-date detailed resource maps, including fire history [1]. The development of a comprehensive spatially explicit map of fire occurrence remains one of the most critical needs for wildfire risk globally [23] and conservation in the SE United States specifically [1,24]. For more than a decade, resource managers have recognized the importance of tracking and monitoring the use of prescribed fire $[1,25,26]$. Differentiating those areas with and without desired fire return intervals would allow managers to focus resources on areas most in need of management actions [1]. Moreover, conservation planning, smoke modeling, prescribed fire planning, fire behavior modeling, and fire risk analyses are sensitive to fire history metrics, such as time since last burn [27].

Public agencies generally track fire occurrence (e.g., using fire perimeters for prescribed and wildfires; point-based fire occurrence databases; prescribed fire permitting systems); however, standards and methods vary among organizations, and a comprehensive, spatially explicit dataset does not exist for the SE. For example, prescribed fire occurrence in Florida is currently tracked and recorded as point data by approximate location through the Florida Forest Service (FFS) Fire Management Information System (FMIS) open burn authorizations (OBA). While this system represents one of the most advanced prescribed fire planning datasets in the country, it can only provide larger-scale summaries of fire activity, as opposed to spatially explicit mapping [13]. Thus, relying solely on systems such as this to address conservation or resource management questions may result in large data gaps and uncertainty.

Alternatively, satellite mapping efforts have long been used to document burned areas and patterns of fire occurrence. Satellite-based methods have the advantage of being replicable in a systematic and standardized way, and methodologies can be extended to alternate locations. Current national directives such as LANDFIRE [28] utilize satellitebased data for updating vegetation, fuels, and disturbance layers. Post-fire monitoring efforts following wildfires such as the Burned Area Emergency Response (BAER) [29] and Monitoring Trends in Burn Severity (MTBS) [25] projects use satellite data to derive 
information on fire severity and intensity, among other things. The MTBS project in particular attempts to map wildfires systematically nationally, although only those fires reported by a state or federal agency greater than 200 ha in the East are mapped and prescribed fires on non-federal lands are generally excluded. Air quality monitoring efforts also use satellite-based data to predict emissions and evaluate/update emissions inventories [30,31]. However, data used in these efforts have limited utility for fine-scale monitoring of patterns of burning in the SE, because they only represent fires reported by state and federal agencies and can miss small fires and fires on private lands.

The Landsat Burned Area (BA) products [32] are a revised version of the Landsat Burned Area Essential Climate Variable (BAECV) products developed and validated by the U.S. Geological Survey (USGS) [33-36] to incorporate Landsat 8 data, accommodate the new Analysis-Ready Data (ARD) format, improve processing efficiency, and extend the data products beyond 2015. The Landsat BA products show promise for systematically monitoring the geospatial extents of fires independent of any type of fire reporting system. The potential for the Landsat BA products to map fire extent and history across the state of Florida needed exploration considering much of the lands burned in Florida and the SE are privately owned. The Landsat BA products could potentially provide additional/unknown burn locations and extents within the SE, including smaller fires (e.g., fires smaller the 200 ha threshold used by MTBS in the eastern US) or those not recorded in other national datasets (i.e., areas where reporting is not required, such as on private property). Even though the Landsat BA products have great potential to assess past patterns of burning, managers may be hesitant to adopt new information without first understanding how they differ from existing, known data [37]. Therefore, assessing and understanding differences between the Landsat BA products and existing fire information is a necessary step to complete before deriving additional data layers or metrics characterizing fire histories, quantifying how those metrics vary across habitats and ownerships, or how those metrics relate to decision making.

The objectives of this study were to first assess existing fire datasets available for Florida and evaluate their strengths and weaknesses for representing burned area using three pilot areas with well-documented fire occurrence; second, use the Landsat BA products to populate a state-wide database for tracking the spatial extents of fires; third, use the Landsat BA products to derive important fire history metrics (e.g., time since last burn, fire frequency, and seasonality ); and fourth, demonstrate how fire history metrics can be used to extend our knowledge of fire occurrence and inform conservation planning. By addressing these four objectives, this study aimed to enhance our understanding of wildland fire characteristics for integration into further analyses specific to landscape planning, conservation, and monitoring using nationally available science products to supplement existing datasets.

\section{Materials and Methods}

\subsection{Study Area}

We used Florida as a test landscape for this study. Florida encompasses nearly $171,000 \mathrm{~km}^{2}$, while burning an estimated 987,000 ha annually [13]. The climate can be described as humid subtropical north of Lake Okeechobee and tropical south of Lake Okeechobee, with an average annual precipitation of $150 \mathrm{~cm}$ [38]. In Peninsular Florida, the dry season is generally cool (e.g., winter), and the warm season is typically rainy and marked by convective storms and tropical systems. In the Panhandle and North Florida, winters are mild but characterized by consistent rainfall from frontal systems. The highest point in Florida is only $105 \mathrm{~m}$ above sea level. Although the variations in topography may be slight or occur over short distances, they can have large effects on the vegetation due to influences on water, soil, and nutrient regimes. Upland ecosystems in the state consist of the pine flatwoods and dry prairies, scrub, temperate hardwood forests, and South Florida rocklands [18]. 
Fire is a strong influence in the composition and structure of the upland ecosystems, and many species that occur in these areas are considered 'pyrogenic' or having fire adaptations [39]. In the wetlands of the state, which include marshes and swamps, hydrology cycles and fire cycles have interacting impacts. Variations in hydroperiods, organic matter accumulation, and fire frequency all have important structural impacts on the wetlands. Fire frequencies, intervals, and rotations vary across the state and range from frequent low-intensity surface fires to infrequent high-intensity crown fires. Prescribed burning is common, occurs throughout the entire year, and is necessary to maintain the high frequency (i.e., 1-3 year) fire-dependent communities. Documented fire intervals, however, range from 1 to $150+$ years [39]. Much of the burnable land within the state currently has a low to moderate departure from historical ranges of burning (in both type and amount, as shown by Fire Regime Group and associated maps [40]). However, uncertainty is considerable in fire intervals because data characterizing fire extent are poor for private lands which account for $70 \%$ of the total land area [15].

\subsection{Datasets}

\subsubsection{Fire Datasets from Landowners}

To help landowners understand the strengths and weaknesses of the Landsat BA products for representing fire history in relation to information they are already familiar with, we asked them to provide us with GIS-based fire information for lands in their ownership/jurisdiction. These landowners represented both public (i.e., U.S. Forest Service, Florida Fish and Wildlife Conservation Commission, Florida Park Service, etc.) and private (i.e., Tall Timbers Research Station, Archbold Research Station, etc.), and they provided fire information in the form of fire occurrence databases and fire perimeters for both prescribed and wildfires. We also acquired nationally available datasets that span ownerships (i.e., the Fire Program Analysis Fire Occurrence Database [41]) and satellite-based thermal detections and fire extent maps. Data types included point, polygon, and raster data (Table 1). The temporal characteristics of the data varied depending on the source. Some fire atlases include data from the 1940s, while some of the newer satellites started data collection in the 2010s and thus do not include data for the early part of the study period. The update frequencies ranged from daily to annually. Furthermore, there was large variability in the attributes included in the different datasets. Some landowners included only prescribed fires, others provided both wildfires and prescribed fires, although not always in a single dataset. Data fields varied widely, and in those instances where fields were similar (e.g., burn date), field definitions were not consistent across the data sources, including within ownerships. Some sources provided only burn unit boundaries that needed to be joined to an additional tabular dataset of prescribed fire history information in order to be evaluated. To instill some level of standardization across the datasets, we restricted our analyses to fires larger than 1 ha occurring from 2006 through 2016, where the different datasets had the greatest amount of temporal overlap. We ultimately focused on landowner-provided datasets from three pilot areas (further described in Section 2.2.3): Apalachicola National Forest (ANF), Big Cypress National Park (BICY) and Eglin Air Force Base (EAFB). 
Table 1. Datasets evaluated for mapping fires in Florida including spatial and temporal characteristics (update availability, period of record, and data coverage timeframe) pertinent to this project. ANF: Apalachicola National Forest, BA: Landsat Burned Area products, BICY: Big Cypress National Preserve, EAFB: Eglin Air Force Base, FFS OBA: Florida Forest Service Open Burn Authorizations, FOD: Fire occurrence database, PLSS: Public Land Survey System, and Rx: prescribed fire. * indicates landowner-provided datasets.

\begin{tabular}{|c|c|c|c|c|}
\hline Data Source & Data Type & Spatial Characteristics & $\begin{array}{l}\text { Dataset Period of Record } \\
\text { (Period Used in Analysis) }\end{array}$ & Wildfire or Prescribed Fire \\
\hline FFS OBA & Point & $\begin{array}{c}\text { 1/4 1/4 section (PLSS) } \\
\text { (through 2008) } \\
\text { Lat/Long } \\
\text { (2008-present) }\end{array}$ & $\begin{array}{c}2004-2016 \\
(2006-2016)\end{array}$ & Prescribed \\
\hline BA & Raster & $30 \mathrm{~m}$ & $\begin{array}{c}1984-2018 \\
(2006-2018)\end{array}$ & Wild and prescribed \\
\hline BICY * & Polygon & & $\begin{array}{c}2006-2018 \\
(2006-2016)\end{array}$ & Wild and prescribed \\
\hline ANF * & Point, Polygon & Varies depending on source & $\begin{array}{c}\text { 1970-2017 (Wildfire FOD) } \\
\text { 1993-2017 (Rx FOD) } \\
(2006-2016)\end{array}$ & Wild and prescribed \\
\hline EAFB * & Polygon & & $\begin{array}{c}1972-2016 \\
(2006-2016)\end{array}$ & Wild and prescribed \\
\hline
\end{tabular}

\subsubsection{Florida Forest Service Open Burn Authorizations}

We also acquired the Florida Forest Service Open Burn Authorizations (FFS OBAs) data from the GIS staff at the Florida Forest Service. The FFS OBA data are stored in an Oracle database; information required for an open burn authorization is recorded daily and includes all open burns (e.g., broadcast burns and pile burns larger than $2.4 \mathrm{~m}$ in diameter) authorized within the state. The database is maintained by the FFS at a statewide level. This is a point dataset and lacks precise spatial extent information for fire events [13,42] but does contain descriptive details about the prescribed fires (i.e., date/time of intended ignition, latitude/longitude coordinates, type of firing pattern, reason for burning, etc.). These records exist from 2004 to the present, although we only focused on the period of interest 2006-2016 while evaluating the suitability of the dataset to spatially represent prescribed fires. Because the FFS OBA data lack perimeters for prescribed burn locations and the accuracy of point locations is suspect, the data were only used in an exploratory analysis where we assessed descriptive characteristics of prescribed burning fire regime characteristics in the state of Florida for trend comparison with other datasets. Except for initial descriptive statistics, all OBAs for sugarcane and other agricultural practices were excluded from analyses. Although agricultural sugarcane burns are highly relevant for air quality estimates [42], the exclusion of agricultural sugarcane fire locations enabled the analysis to focus on areas most relevant for habitat conservation concerns.

\subsubsection{Landsat Burned Area Products}

We initially acquired the Landsat BA products for Florida for the period 2006-2016 [33,43]. The USGS provided the BA data in the Analysis-Ready Data (ARD) format, a top-level product meant for analyzing time-series data that have known data quality [43]. This national product uses a suite of spectral indices quantified as single-scene, pre-fire condition, and change from pre-fire condition as inputs to a gradient boosted decision tree model. The model generates a burn probability surface for each Landsat image. Categorical burned areas with a minimum mapping unit area of 2 ha are identified by applying thresholds and region growing to the burn probability surfaces [32]. The resulting Landsat BA products have $30 \mathrm{~m}$ spatial resolution and are generated for Landsat images with less than $80 \%$ cloud cover. The BAECV products were validated nationally using both commercial highresolution satellite data [35] and Landsat reference data [36]. Both approaches were used 
to provide updated validation metrics for the more recent Landsat BA products [32] and indicated an omission error rate of $19 \%$ and a commission error rate of $41 \%$ when validated with high-resolution imagery, and an omission error rate of $40 \%$ and a commission error rate of $28 \%$ when validated with Landsat imagery and excluding agricultural areas. These studies indicated omission and commission errors of Landsat-based BA products vary depending on whether a national or regional perspective was assessed [32,35,36].

We first evaluated the Landsat BA products from 2006 to 2016 against FFS OBA data and specific landowner datasets consisting of fire records provided by managers at three pilot areas (EAFB, ANF, and BICY). These three sites have large-scale prescribed fire programs and fire-dependent ecosystems, and all keep records of known fire locations. Additionally, these areas are known to be of specific conservation interest due to being within larger focal area landscapes hosting species of great concern in the state of Florida (EAFB falls within the Gulf Coastal Plain Ecological Partnership, and BICY is part of the Greater Everglades area) or containing globally recognized biological diversity hotspots (ANF). Comparison of datasets at the three pilot areas would highlight the strengths and weaknesses of the Landsat BA products and provide insight as to how the products would perform in other areas where information about past fire is lacking, such as private lands.

For each of the three pilot areas, we held a meeting with one to three of the fire/land managers from that location, either in person or via web conferencing methods (a total of eight individuals met with us). Fire management officers, burn bosses, and fire ecologists were represented in these stakeholder groups. The fire and land managers provided local expertise to help us to better understand when and where BA-derived products were performing well and where they seemed to be missing the mark. Specifically, through the qualitative stakeholder engagement process, we learned that the classified BA product consistently under-estimated burned area extent relative to in-person and ground-based estimates of burned area extent. This effort guided the revision of the BA probability threshold from the original $>96 \%$ [32] to a locally appropriate $>90 \%$ probability.

For each year, we created mosaics of the annual BA Burn Probability (BP) product from the 20 ARD tiles covering Florida. The annual BP product spans an entire calendar year (i.e., Jan 1 through Dec 31) and indicates the maximum BP within the year. Pixels in the BP mosaic with burn probability values between 90 and $100 \%$ were then classified as burned areas (we refer to this dataset as $90 \mathrm{BP}$ ). We filled holes $<1$ pixel using a 'clump' tool, and then removed patches less than 10 contiguous $30 \mathrm{~m}$ pixels using a 'sieve' tool. The associated burn dates for the annual 90BP datasets were also derived following Hawbaker et al.'s approach [32]. We used the 90BP dataset as a mask, and for the burn date (BD), the scene date (i.e., Landsat acquisition date) associated with the first image identifying a pixel as burned was used. The 90BP and BD datasets were converted to feature classes (i.e., vectors). The newly created raster and vector datasets were then used to assess spatial extents and temporal characteristics of fires, including fire regime metrics described below.

\subsection{Comparison of Fire Datasets}

Each dataset presented in this study has advantages and disadvantages. Perimeterand point-based datasets are imperfect and spatially biased (towards public land), but still widely used and trusted by land managers. The already published Landsat BA products provide spatially unbiased data but tend to show substantial omission errors in this region of the United States and are not delivered in a format conducive to rapid use by land managers. While our objective was not to formally validate the Landsat BA products as they have been independently validated in other published papers $[32,35,36]$, we did present a comparison of the datasets. Specifically, we compared estimates of the total burned area using the derived 90BP product compared to the landowner and OBA datasets at each of the three pilot areas. In addition, using an annual time step (2006-2018), correlations in total area burned, as estimated by the different datasets, were generated for each of the pilot areas. With this approach, the perimeter and point-based datasets 
enabled us to comparatively explore the utility of the Landsat BA products to provide spatial information about burned areas in a replicable fashion across a landscape.

\subsection{Fire Metrics}

Fire history and seasonality metrics were derived from the 2006-2018 90BP and BD datasets; we added 2017 and 2018 BA products based on updated product availability after our initial comparison of fire datasets for the period 2006-2016. The metrics we derived included (1) fire frequency (number of times burned), (2) time since last burn, (3) year of last burn, (4) longest fire-free interval, (5) time of year (spring, summer, fall, winter), and (6) seasonality (growing vs. dormant). These fire regime characteristics are important for managers (especially in Florida) because they can inform planning and conservation efforts, as well as tactics on wildfires and prescribed fire prioritization models. Unless otherwise noted, the fire metric derivations were performed on raster datasets and then converted to vector data for display and query purposes as a final step. We define the metrics below and detail their derivations.

Fire frequency (FRQ) refers to the number of times a specific location has burned in the period of record or for a given period of interest if a subset of the total fire record $[44,45]$. Burned area is categorically differentiated from the unburned area, and the total number of occurrences is 'summed' over a pixel through time. This value cannot be greater than the number of years in the fire history record.

Time since last burn (TSLB) is the measure of time from a specific date in time back to the last date of a detected or known fire (adapted from [46]) within the period of record; it is only calculated in locations where at least one burn has occurred. Units can be months, days, or years. Since we used annual burned areas to populate the database, TSLB is reported as the number of years from "present" to the last identifiable burn (e.g., where "present" would be 2017 for a 2006-2016 dataset, and 2018 for a 2006-2017 dataset). This value cannot be greater than the number of years in the fire history record.

Year of last burn (YLB) is the year of the last known or identified fire in a location; it corresponds with the TSLB for the period of record. For this study, the four-digit year was used to designate this information (e.g., YLB $=2008$ ). This value cannot be outside the range of years in the fire history record, and values are only applied to locations that have burned at least once.

The fire-free interval refers to the tally of years when no burn is detected between consecutive fires, reported in units of years. We calculated the longest fire-free interval (LFFI) at a pixel level for the 13 year period by determining the value for every fire-free interval and retaining the maximum value. For example, if a place burned in 2006 then 2008 and not again until 2017, the LFFI would evaluate the first fire-free interval (between 2006 and 2008, FFI = 1) against the next interval (between 2008 and 2017, FFI = 8), and the LFFI would be reported as 8 years. For places that never burned, this value should be equal to the time period of record used in the analysis (e.g., for the 2006-2018 dataset, the LFFI = 13).

We define time of year as the grouping of months into the four seasons; Spring (Mar-May); Summer (Jun-Aug); Fall (Sep-Nov); and Winter (Dec-Feb). The first date of detection of high probability (e.g., $>90 \% \mathrm{BP}$ ) fire pixels was recorded in the BD dataset as a day of year value corresponding to the date of acquisition. We used this date to categorize time of year into the four seasons.

Seasonality refers to whether the burn occurred during the growing season (March 15-October 14) or dormant season (October 15-March 14). These dates were chosen based on relative growing season dates as defined by fire managers in the state of Florida [47] and in the literature [48] and are to be considered a generic surrogate.

Products in the database were based on a calendar year; thus, in terms of the number of fires, if a pixel burns more than one time within a calendar year it is only counted one time. Additionally, values for time since previous fire are reported at an annual level, even if they may have been less than 12 months apart. Furthermore, late-season misattribution 
is possible using this method-fires that occurred in November or December of a given year may not be detected until the following calendar year, in which case the 'year' of the burn would be misattributed. In addition, we do not differentiate between prescribed fires and wildfires since the BA dataset cannot distinguish fire type and both types of fire can meet management objectives and impact species habitats; as such, both are an important part of the fire regime evidence used to inform conservation-monitoring decisions.

\subsection{Example Conservation Application of Fire History Metrics}

Maps of the annual area burned, as well as the FRQ, YLB, TSLB, and LFFI fire metrics were generated for the entire state. We used the annual area burned maps to derive fire rotations [49] for select landcover types within Florida that are important habitats for a variety of fire-dependent species, such as gopher tortoises, sandhill cranes, and Sherman's Fox Squirrels, and many other species of greatest conservation need (SGCN; [50]). Fire rotations are the amount of time (expressed in years) required to burn a specified proportion of an area of interest [44,49]; they describe the rate of burning in an area [46] and should be equal to the mean fire return interval [49]. For each habitat of interest, we divided the total number of years in the period of record (13 years) by the proportion of area burned. To further highlight the utility of the fire metrics, the FRQ metrics were evaluated for the ANF in relation to indigo snake habitat (unpublished data from Florida Fish and Wildlife Conservation Commission-Fish and Wildlife Research Institute), and the statewide TSLB and LFFI fire history metrics were evaluated on public and private ownerships [15] using an example focused on natural pinelands, a fire-adapted ecosystem with conservation interests in Florida [50]. The natural pinelands are a broad land cover category that includes dry flatwoods, mesic flatwoods, scrubby flatwoods, upland coniferous, upland mixed woodland, and upland pine sites as defined using the Florida Cooperative Land Cover Map [51].

\section{Results}

\subsection{Comparison of Landowner Perimeter, OBA, and Landsat 90BP Datasets}

In compiling sources of the burned area from the different datasets, the diversity of ways in which fire data were recorded for burn units and prescribed burns were evident (Figure 1). Some landowners recorded an entire burn unit for a prescribed fire as having burned even if the burn was patchy or incomplete; other landowners subset the burnable area within the unit or GPS the actual post-fire burn perimeter (and the variability of effects within the burn). The variability in the perimeter collection method resulted in source-dependent uncertainty in total burned area extent, limiting the usefulness of such data for validation efforts.

In addition to the landowner compiled perimeter dataset, the FFS OBA dataset was also considered. Although spatially explicit information about the extent of burns is not included in the FFS OBA dataset, these data reveal the extraordinary amount of prescribed burning in the state of Florida. Between 2006 and 2016, a total of 996,797 requests were made to the FFS (pile and broadcast burns). Broadcast burns accounted for $25 \%$ of all approved authorizations $(n=250,978)$ and requests for a total of 9.3 million hectares were submitted. Of this, $7 \%(n=16,855)$ of the broadcast burns requested were for a continuation of a previous authorization (i.e., to finish a burn that was not completed previously for any reason) and account for approximately 870,000 ha of the requested area. 

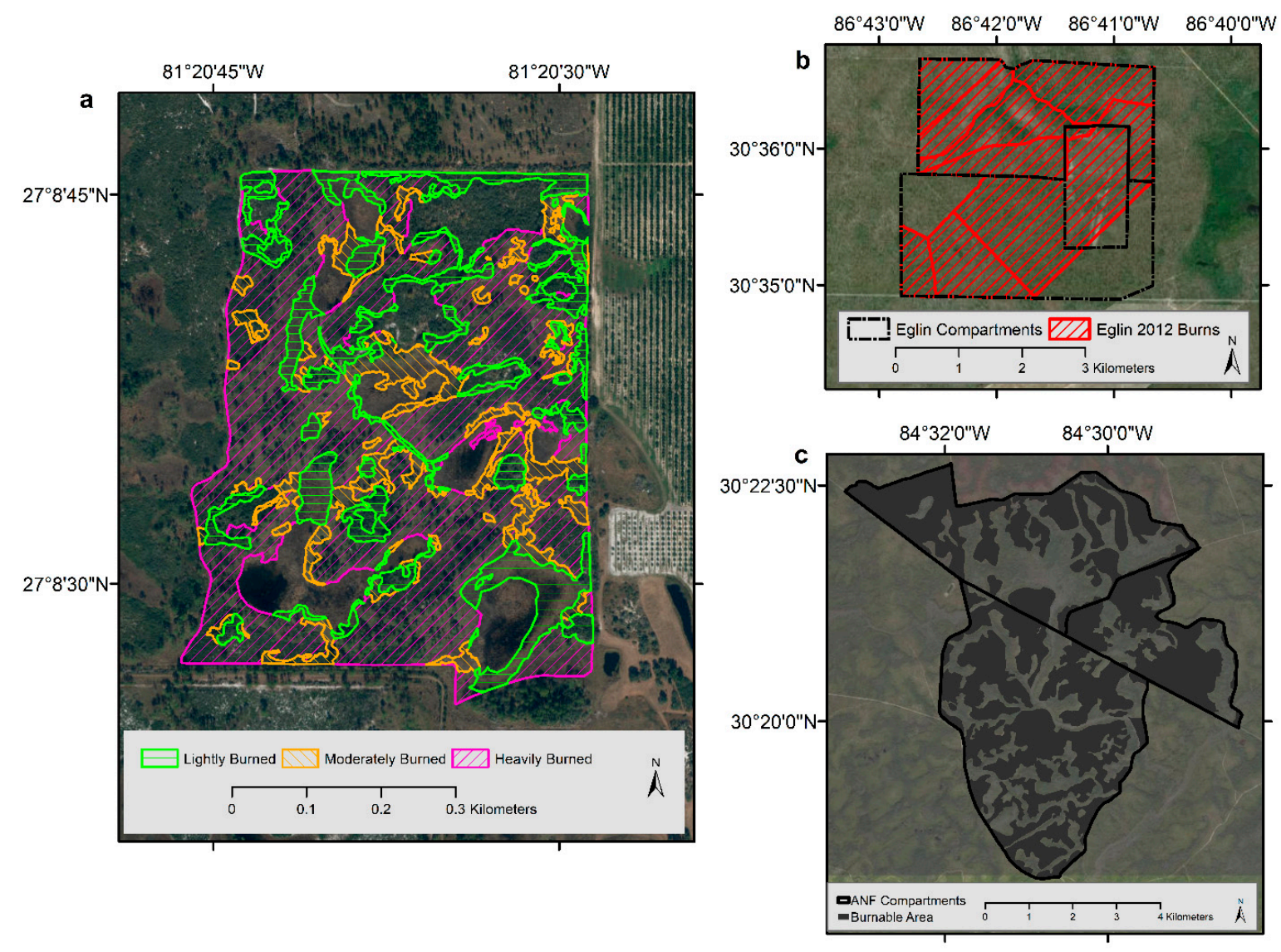

Figure 1. Fires are mapped in different ways by different entities. Here are three examples for three different ownerships: (a) Archbold Research Station maps post-fire intensity, as shown in this 2015 prescribed burn; (b) Eglin Air Force Base takes advantage of roads and natural barriers to apply fire within larger burn units, so mapped burns (red lines) can either overlap unit boundaries (dashed black lines) or not completely burn within a unit; (c) Apalachicola National Forest maps only the burnable areas in units where fire was applied.

Seasonal patterns in burning across the state of Florida (as derived from the FFS OBA data) showed prescribed burning activity is inversely related to the wildfire season (e.g., April through November) in the SE (Figure 2), a finding that reaffirms historical assessments $[52,53]$. Excluding sugarcane burning, most burn authorizations were requested in the winter and early spring (December-March), and requests declined in April and May as wildfire activity increased with seasonal drought patterns. In general, most authorizations occurred in February, which also consistently had the highest prescribed fire activity. Across all years, the number of authorizations was highest between January and March, which generally corresponds to the three months with the most area burned. April and May have shown a trend in increasing numbers of requested authorizations. The OBA data provided a generalized view of when and where the prescribed fires occur, and these descriptive statistics were a useful baseline for understanding when burned areas should have been detected by the Landsat products across all land ownerships.

We then compared the 90BP Landsat data with the OBA data and landowner-provided data to assess the extent of burning at our three pilot areas, EAFB, ANF, and BICY. Visual and preliminary analyses of records from the three pilot areas confirm the high amount of burning done on each ownership. The landowner prescribed fire data tended to report less burned area (391,192 ha total) than was requested in the OBA $(502,249$ ha total) at EAFB (78\% of OBA on average) and more burned area than the OBA at ANF $(345,306$ ha vs. 336,713 ha; $3 \%$ more than the OBA) and BICY (187,785 ha vs. 157,008 ha; $20 \%$ more than the OBA). Differences in reported burned area from the OBA and landowner prescribed fire datasets were expected because of variability in reporting methods (e.g., area that 
actually burned vs. area of burn unit requested). However, in all three areas, the correlation between the annual burned area in the OBA and landowner prescribed fire data was 93\%, $97 \%$, and $90 \%$, for EAFB, ANF, and BICY, respectively. This indicates that the OBA and landowner prescribed fire datasets report similar information about the extent and timing of burning even if they differ in the absolute amount of burned area.

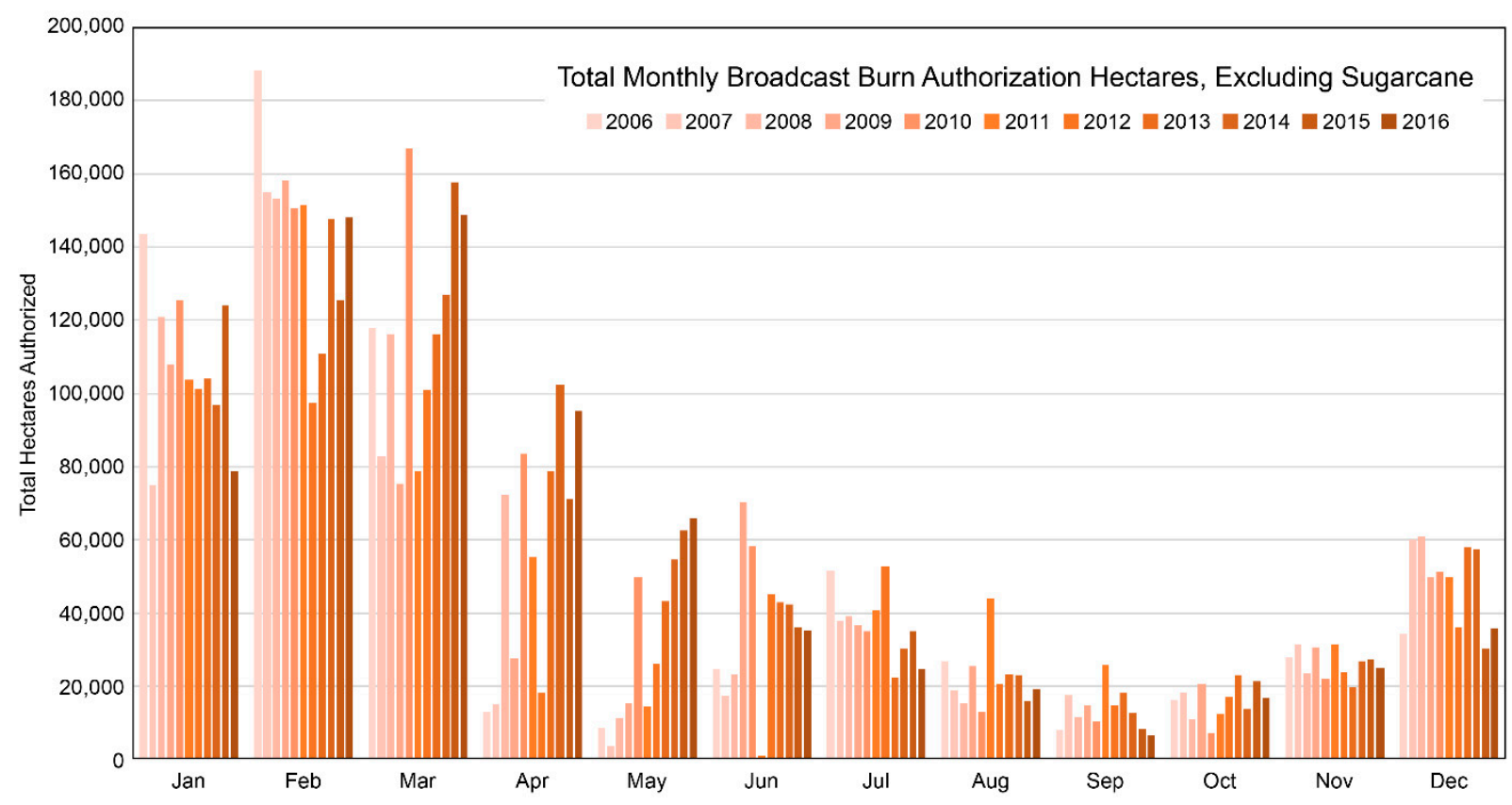

Figure 2. Monthly burning trends in area for broadcast burn authorizations in Florida for the period 2006-2016, derived from the Open Burn Authorization (OBA) dataset.

Differences in the total burned area were more pronounced when the remotely sensed BA products were considered, in part because of the detection rates of the BA products but also because of how the burned area was reported in the OBA and landowner datasets (e.g., planned area burned or burn unit area vs. remotely sensed burned area). Consequently, in all three pilot areas, the OBA and the landowner datasets (combined wildfire and prescribed fire data) reported a larger amount of burned area than the 90BP data. For example, the annual burned area in the 90BP averaged $36 \%$ of the OBA data (range $4-133 \%$ ) and $29 \%$ of the landowner data (range 3-64\%). The 90BP data were more similar in some years than in other years when compared against the OBA and landowner datasets. In $2006,90 \mathrm{BP}$ captured $48 \%(10,885 \mathrm{ha})$ of the total area reported burned by wildfires and prescribed fires in the landowner dataset (22,595 ha, combined) at EAFB, while in 2012 only $10 \%$ was captured ( 3765 ha $90 \mathrm{BP}$ vs. 36,583 ha landowner dataset). Correlations between the 90BP data and the OBA and landowner data were lower than correlations between the OBA and landowner data for all three pilot areas. At EAFB, the annual burned area in the 90BP data had 16\% correlation with the OBA data and 15\% with the landowner data. However, the agreement was much better at ANF where the correlation in the annual burned area was $90 \%$ between the $90 \mathrm{BP}$ and OBA data and $80 \%$ between the $90 \mathrm{BP}$ and the landowner data. At BICY, the correlation was low between the 90BP and OBA data (1\%) but greater between the 90BP and landowner data $(80 \%)$. The BICY landowner data on average showed much less agreement with the 90BP data than the other two pilot areas (14\% BICY; $25 \%$ EAFB; $48 \%$ ANF), likely due to the uniqueness of the area-it largely comprises wetlands, a landcover type shown to have lower detection rates for fires $[35,36]$. At EAFB and BICY, the 90BP datasets showed slight decreasing trends in burned area over time and a slight increase at ANF.

We highlight EAFB (Figure 3a) to visually illustrate the differences in the datasets; the EAFB fire data (i.e., landowner-provided datasets) have been extensively used for a variety 
of research applications $[1,13,54,55]$. Visualizing the FFS OBA points (Figure $3 b$ ), traditional 'burn unit' mapping (e.g., the landowner dataset showing the burn units that were burned, which show the area within which fire was applied; Figure 3c), and the 90BP-based fires detected on Eglin AFB (Figure 3d) shows that each dataset has different strengths and weaknesses. For example, because the FFS OBA only provided point locations, ascertaining the exact extent of fire is not possible; conversely, quantifying the number of requests to burn using only the landowner or 90BP methods is difficult. Even though the three different datasets map fires on Eglin AFB differently, the OBA points and 90BP burned patches were often in close proximity, and the landowner perimeters and 90BP burned patches often had substantial overlap. All three datasets generally show similar spatial and temporal patterns. However, at finer scales, they yield much different results spatially, particularly in terms of area burned within burn unit boundaries. Neither the FFS OBA nor the landowner-provided fire data can quantify the fine-scale pattern of fire across the landscape. Although the Landsat BA data do show a mosaic of burning, they do not detect all burned areas $[35,36]$ at the $90 \% \mathrm{BP}$ threshold selected and may miss low-intensity burns, under-canopy burns, and areas where vegetation rapidly recovered after fires.
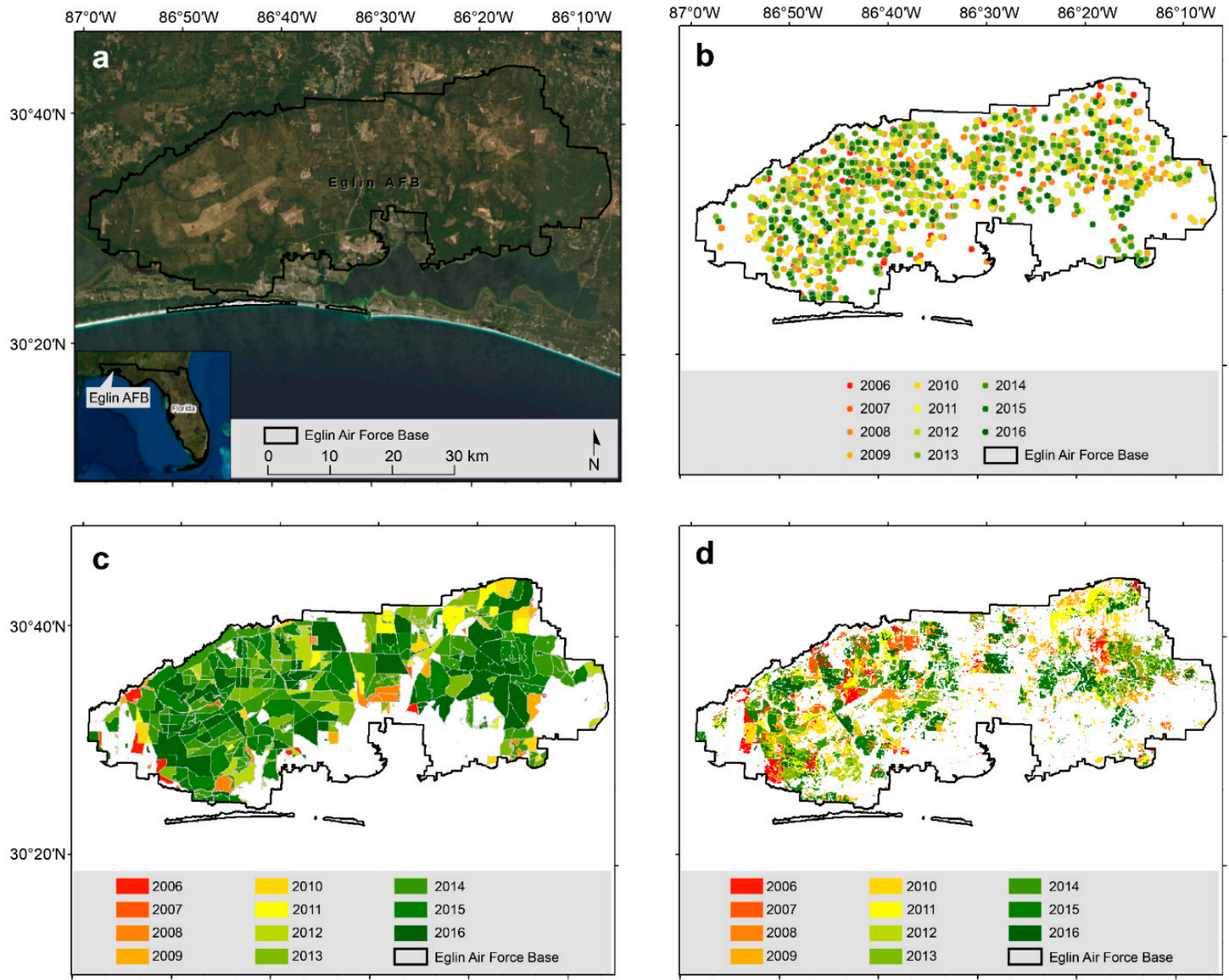

Figure 3. Displaying the fire history using different data sources results in different mapping outputs for (a) Eglin Air Force Base (EAFB), Florida. (b) Florida Forest Service Open Burn Authorization data for the period 2006-2016 partially depict the amount of burn authorizations requested but not an exact location; (c) landowner-provided fire history data illustrate when fire was applied to a burn unit; (d) fire extents derived by thresholding the Landsat burn probability ( $\geq 90 \%)$ showing when and where a fire was detected, including the mosaic within a burn unit. 


\subsection{Fire History Metrics and Example Applications}

We generated statewide fire history metrics from the 90BP data. Although the monitoring methods between the OBA, landowner provided, and 90BP-based data differ, the 90BP dataset is the only one that consistently monitors burned areas with spatial detail representing within-fire heterogeneity across Florida. The fire history metrics provide a raster representation of the FRQ, YLB, TSLB, LFFI, and the seasonality of fires. The methods for producing fire history metrics were tested on the three focal areas then generated statewide (for the period 2006-2018). Due to the $30 \mathrm{~m}$ resolution of the data, we focused on the three pilot areas for visualization purposes. An example of how these metrics appear when mapped is highlighted for the Apalachicola National Forest (Figure 4), where different patterns appeared across the landscape depending on which metric is evaluated. In addition, an example of how FRQ can be visualized to support monitoring of an individual species at a site such as the Apalachicola National Forest is shown in Figure 5. Finally, average TSLB and average LFFI were evaluated for natural pinelands on Florida's public and private lands and mapped at a 10-km resolution for visual clarity (Figure 6).
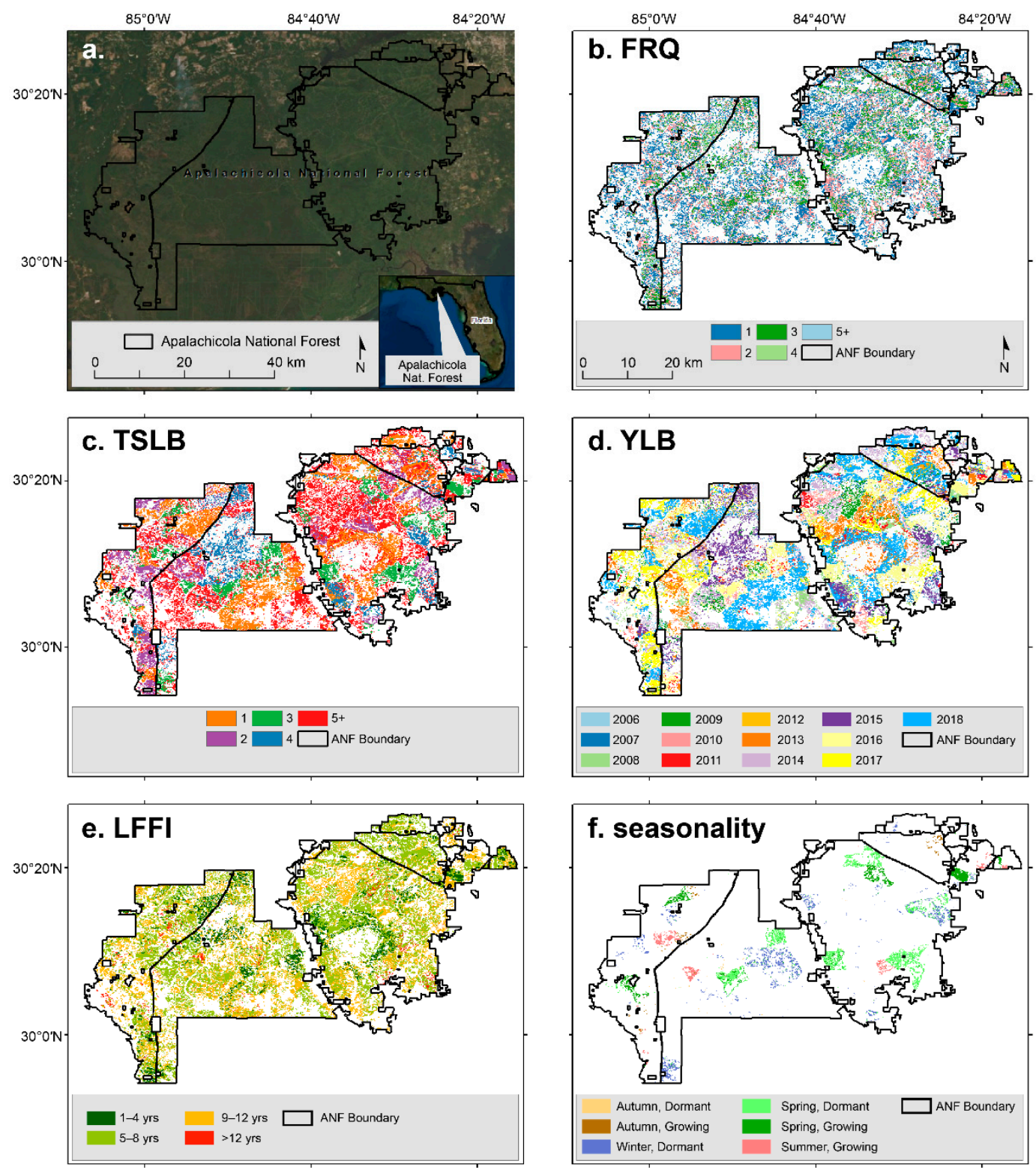

Figure 4. Fire history metrics derived for the (a) Apalachicola National Forest (ANF) spanning the Table 2006 to 2018 illustrate 
that landscape patterns are easily discerned. Fire metrics derived from the Landsat burn probability products include: (b) the number of times burned (FRQ), (c) time since last burn (TSLB) in years, (d) year last burned (YLB), and (e) longest fire-free interval (LFFI); and (f) the seasonality of burning for the year 2016 was derived from the burn date products.

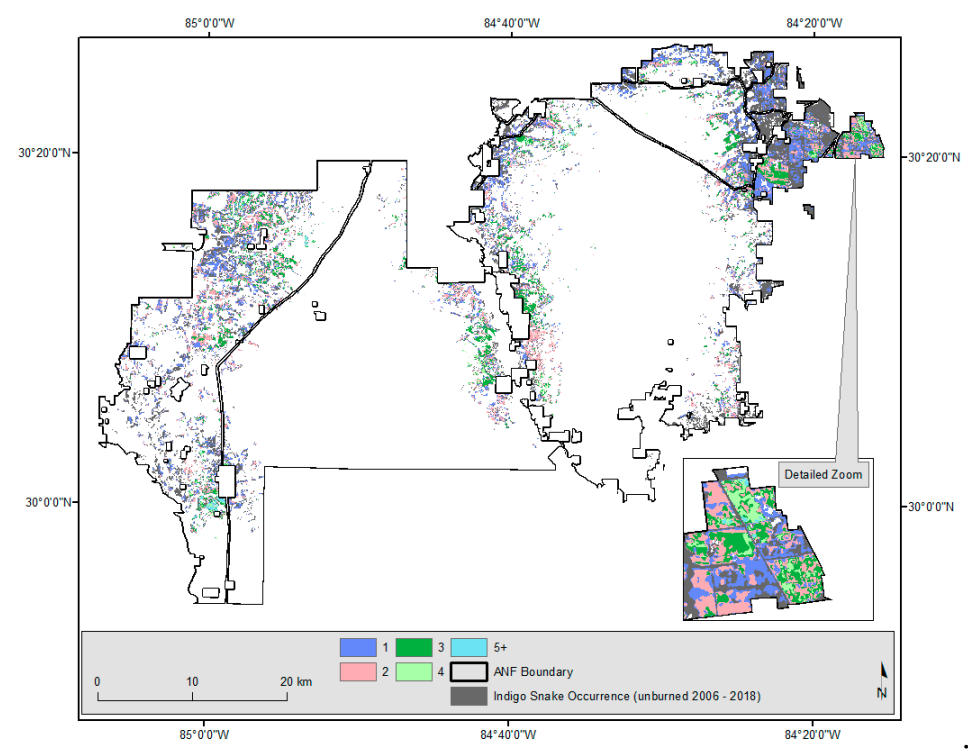

Figure 5. Fire frequency (2006-2018) restricted to Indigo snake occurrence locations is shown across the Apalachicola National Forest (ANF) at $30 \mathrm{~m}$ resolution. This example application demonstrates how the FRQ fire metrics can be potentially used to guide species-level habitat management activities. White indicates parts of the ANF outside of Indigo snake occurrence data.
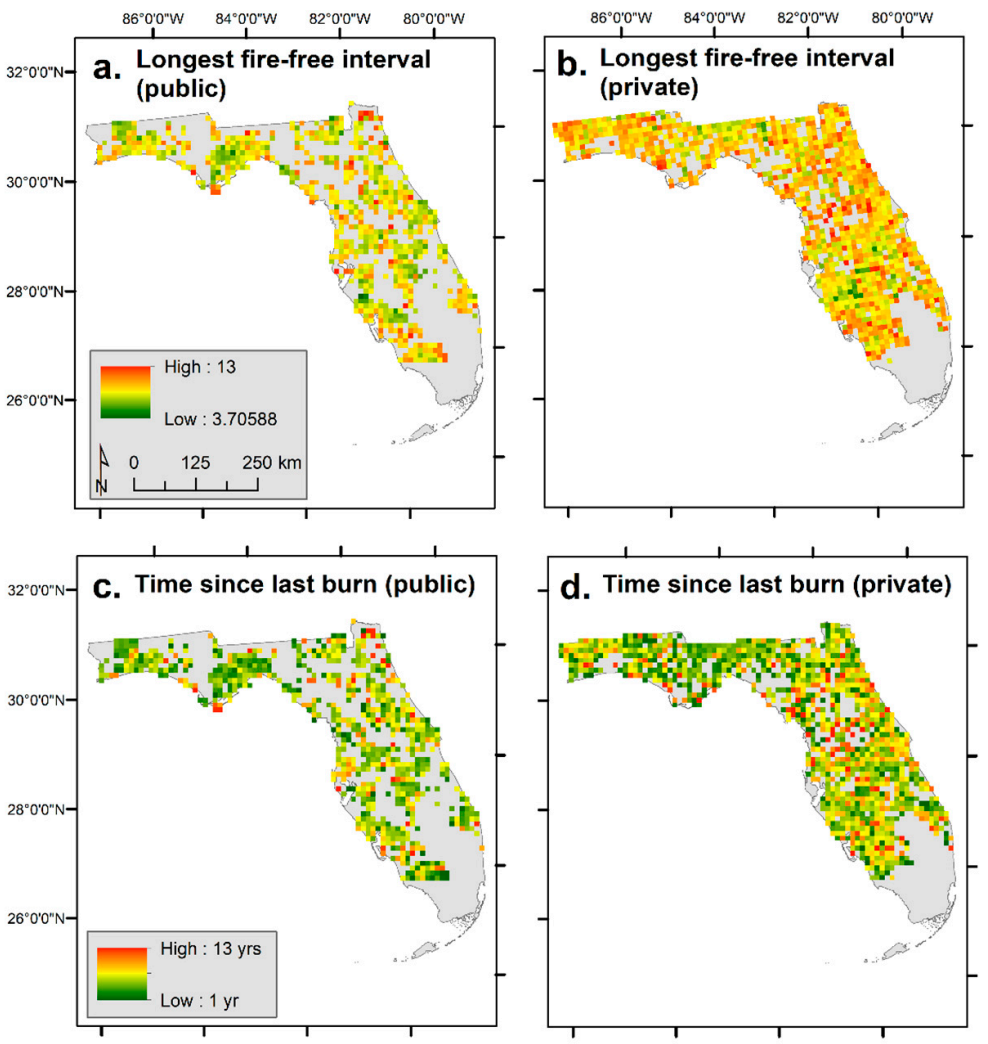

Figure 6. Fire history metrics for natural pinelands including (a) the longest fire-free interval (LFFI) on public land, (b) the LFFI on private land, (c) time since last burn (TSLB) on public land, and (d) TSLB on private land. Units in years. The $30 \mathrm{~m}$ resolution LFFI values were averaged within $10 \mathrm{~km}$ grid cells to improve visibility. Legends are identical for $(\mathbf{a}, \mathbf{b})$ and for $(\mathbf{c}, \mathbf{d})$. 
The statewide results indicated that although some places have never burned, other places have burned up to 13 times, annually from 2006 through 2018. In the places that burned, the YLB ranged from 2006 to 2018, and the TSLB ranged from 1 to 13 years. The LFFI ranged from 1 to 12 years. Our 90BP-derived burned area data do not have monthly resolution, because we used annual products. However, we did attempt to resolve the seasonality of burning using the first date of detection for a 90BP pixel, but these data are hard to correlate to specific burns due to the lag time of sensor overpass when compared to a fire (i.e., it can be $>1$ week up to a few months depending on location [32]). Thus, this metric was not analyzed beyond an exploratory phase for this work.

We selected a subset of landcover classes of conservation interest within the state of Florida to evaluate the potential use of the BA products for deriving fire rotations (Table 2). The extension of the science-based BA products to management applications for monitoring ecosystems and habitats is an example of stakeholder-driven science [56]. Habitat loss is a primary threat to the conservation of SGCN; thus, habitat monitoring of these systems through time to evaluate the impact of fire on them is critical. As Table 2 shows, the results vary by landcover and are generally longer than published fire intervals for these systems [39,57] when evaluated at the scale of the entire state. For example, according to those published values, the sandhills target a 1- to 3 year mean fire return interval, while the value calculated from 90BP data suggests a 23 year rotation statewide. However, the fire rotation calculated for the sandhills on the ANF was 9 years.

Table 2. Total hectares burned within the state of Florida for specific habitats of interest (based on Cooperative Land Cover Site Classification v3.2.2; [51]). These values were derived from burned area produced by thresholding the Landsat burn probability product $(\geq 90 \%)$ occurring solely in the state, based on 13 years of data (2006-2018). Fire rotations [46] are compared to published fire interval values [39] for these systems.

\begin{tabular}{|c|c|c|c|c|c|}
\hline & Site Classification & $\begin{array}{l}\text { Total Area of Site } \\
\text { Classification (ha) }\end{array}$ & $\begin{array}{l}\text { Total Area Burned, ha } \\
\text { (\% of Site Area) }\end{array}$ & Fire Rotation (Years) & $\begin{array}{c}\text { Published Fire Interval } \\
\text { (Years) }\end{array}$ \\
\hline Sandhill & Sandhill & 313,937 & $178,610(57 \%)$ & 23 & 1 to 3 \\
\hline \multirow{8}{*}{ Ephemeral Wetlands } & Baygall & 15,335 & $3005(20 \%)$ & 66 & $\mathrm{~N} / \mathrm{A}$ \\
\hline & Bottomland Forest & 4919 & $166(3 \%)$ & 386 & $\mathrm{~N} / \mathrm{A}$ \\
\hline & Dome Swamp & 14,348 & $3625(25 \%)$ & 51 & $\mathrm{~N} / \mathrm{A}$ \\
\hline & Prairies and Bogs & 15 & $6(36 \%)$ & 36 & $\mathrm{~N} / \mathrm{A}$ \\
\hline & Wet Prairie & 158,835 & $77,264(49 \%)$ & 27 & 2 to 4 \\
\hline & Seepage Slope & 2203 & $3489(158 \%)$ & 8 & 2 to 3 \\
\hline & Shrub Bog & 5782 & $2865(50 \%)$ & 26 & $\mathrm{~N} / \mathrm{A}$ \\
\hline & South Florida Bayhead & 8593 & $691(8 \%)$ & 162 & $\mathrm{~N} / \mathrm{A}$ \\
\hline \multirow{2}{*}{ Ephemeral Wetlands ${ }^{1}$} & Isolated Freshwater Marsh & 48,029 & $13,898(29 \%)$ & 45 & $\mathrm{~N} / \mathrm{A}$ \\
\hline & Marshes & 363,962 & $89,461(25 \%)$ & 53 & $\mathrm{~N} / \mathrm{A}$ \\
\hline \multicolumn{2}{|c|}{ Ephemeral Wetlands, All } & 622,022 & $194,469(31 \%)$ & 42 & \\
\hline \multirow{4}{*}{ Scrub } & Coastal Scrub & 7913 & $1725(22 \%)$ & 60 & $\mathrm{~N} / \mathrm{A}$ \\
\hline & Oak Scrub & 786 & $148(19 \%)$ & 69 & 5 to 30 \\
\hline & Sand Pine Scrub & 89,422 & $27,624(31 \%)$ & 42 & $\mathrm{~N} / \mathrm{A}$ \\
\hline & Scrub & 63,877 & $31,104(49 \%)$ & 27 & $\mathrm{~N} / \mathrm{A}$ \\
\hline Pine Rockland & Pine Rockland & 6825 & $1827(27 \%)$ & 49 & 3 to 7 \\
\hline \multirow{3}{*}{ Natural Pineland } & Dry Flatwoods & 995 & $127(13 \%)$ & 102 & $\mathrm{~N} / \mathrm{A}$ \\
\hline & Mesic Flatwoods & 536,214 & $472,357(88 \%)$ & 15 & 1 to 4 \\
\hline & Scrubby Flatwoods & 37,886 & $20,555(54 \%)$ & 24 & 5 to 15 \\
\hline \multirow{3}{*}{ Natural Pineland ${ }^{2}$} & Upland Coniferous & 113,267 & $87,146(77 \%)$ & 17 & $\mathrm{~N} / \mathrm{A}$ \\
\hline & Upland Mixed Woodland & $\begin{array}{c}110,207 \\
4427\end{array}$ & $3909(88 \%)$ & 15 & 10 to 20 \\
\hline & Upland Pine & 66,708 & $99,419(149 \%)$ & 9 & 1 to 3 \\
\hline \multicolumn{2}{|c|}{ Natural Pinelands, All } & 759,498 & $683,512(90 \%)$ & 14 & \\
\hline Dry Prairie & Dry Prairie & 63,087 & $138,558(220 \%)$ & 6 & 1 to 2 \\
\hline Coastal Strand & Coastal Strand & 2713 & $297(11 \%)$ & 119 & occasional \\
\hline $\begin{array}{c}\text { Tropical Hardwood } \\
\text { Hammock }\end{array}$ & Mesic Hammock & 36,018 & $2951(8 \%)$ & 159 & frequent to rare \\
\hline \multicolumn{2}{|c|}{ Grand Total } & $1,966,099$ & $1,260,824(64 \%)$ & & \\
\hline
\end{tabular}

Figures 5 and 6 show two examples of how the fire metrics can be applied to conservation issues. Habitat degradation due to fire exclusion can result in the loss of viable populations of species such as the indigo snake and gopher tortoise (both of which are 
considered to be SGCN; [51]). These species prefer open forest areas maintained by frequent fire to thrive. By overlaying fire metrics such as FRQ onto species occurrence data for the indigo snake (Figure 5), we can visually identify and locate those areas that need fire reintroduction. Furthermore, this information can be used for habitat restoration planning purposes and to help prioritize areas for prescribed fire implementation. For example, there is 36,400 ha of indigo snake habitat on the ANF, of which 22,400 ha $(61.7 \%)$ have burned. When considering total indigo snake habitat on the ANF, 5700 ha $(15.7 \%$ of total habitat) have burned between three and six times (i.e., FRQ $=3$ to 5+; Figure 5), while 16,700 ha ( $45.9 \%$ of total habitat) have burned less than twice (i.e., FRQ $=1$ or 2 ) between 2006 and 2018. These less frequently burned locations may need to be assessed further to determine indigo snake habitat suitability.

In Figure 6, we highlight the statewide differences between fires in natural pinelands on public and private lands using the average LFFI and TSLB metrics. Natural pineland represents $5 \%$ of the Florida land cover, with $47 \%$ and $53 \%$ of the natural pineland occurring on public land and privately owned land, respectively. Fire history metrics were only calculated where a burned area had been identified at least once in the 2006-2018 period; $60.4 \%$ of the public natural pineland burned at least once during this period, compared to only $26.1 \%$ of the privately-owned natural pineland. Where burned areas did occur, fire history metrics indicated more consistent burning on public lands. Between 2006 and 2018, the LFFI averaged 7.5 years on public natural pineland compared to 8.2 years on private natural pineland, while the TSLB averaged 4.6 years on public natural pineland compared to 5.4 years on private natural pineland.

\section{Discussion}

The lack of appropriate fire management has been identified as a major source of stress for fire-adapted habitats in Florida (see [51]). This includes increased wildfire severity due to successful fire suppression activities and a lack of prescribed fire at appropriate intervals. Before this analysis, a systematic and comprehensive way to characterize fire across the state did not exist. A major result of this work is that we have advanced our ability to track fire regimes across the state of Florida. In this analysis, we used the USGS Landsat BA products to develop fire metrics (2006-2018) that detail fire history and occurrence in habitats across the state, including those critical for the conservation of Florida's firedependent ecosystems and species. For example, monitoring species' response to fire management and altering actions to improve the productivity of the species is identified as a need in FWC's Species Action Plans for Sherman's fox squirrel, Big Cypress fox squirrel, and the Florida sandhill crane, among others. Further, these metrics can be used in conjunction with species occurrence data to assist with monitoring (Figure 5) or can be further evaluated on fire-dependent habitats across ownerships (Figure 6). Intersecting the fire metrics with species occurrence data and specific habitats can provide a clearer picture of fire/species interactions and responses, which is an important part of land management. Our results highlight a subset of important Florida ecosystems for these species and compared the results derived from BA products to published values. The extension of the science-based BA products to management applications engages stakeholders in the scientific process and is valuable for improving both science and products.

\subsection{A New Approach for Deriving Fire Regime Information}

Understanding fire regime characteristics is critical for natural resource conservation planning. However, many sources of fire data are not independently suitable to derive fire history metrics because the data exclude small wildfires and prescribed fires, or they lack adequate spatial or temporal information. Using the state of Florida as a case study area for a proof of concept of mapping fire metrics, our work shows the value of using remote sensing-based datasets to address stakeholder-driven needs in order to provide actionable information. This analysis demonstrates how recently developed burned area products, specifically the Landsat BA product, can be extended to produce fire history 
information directly relevant and useful for land managers. Fire metrics are important for land managers (especially in the SE) who have landscape planning, monitoring, or conservation reporting responsibilities. This comprehensive suite of spatial fire products allows us to query how fires are being used to meet specific management challenges including species occurrence and habitat models, ownership, and landcover classifications. The results can be especially useful if used in conjunction with existing datasets-FFS OBA, landowner-provided fire history/occurrence data, and other efforts such as MTBS. The Landsat BA-based results can also be adapted to create annual or seasonal composites or incorporate local and regional specificities for burn detection (e.g., retaining a different threshold of burn probabilities in different ecosystems if $90 \%$ is not representative of the fires).

\subsection{BA Fire Metrics Complement Existing Data}

To date, Florida does not have a standardized way of capturing the spatial extent of fires across its diverse ownerships. The closest data source available for spatial information about fires is the FFS OBA database, which tracks prescribed fire authorizations by a point with latitude/longitude coordinates. The lack of a statewide spatial database of fire extents and occurrence in Florida means that the FFS OBA dataset is an important surrogate to understand coarse-scale fire history information and higher-resolution temporal patterns. The FFS OBA was designed to support Florida statutes requiring authorizations for burning on any land in the state, so the FFS OBA dataset is important for many types of analyses, such as emissions inventories and prescribed fire history analysis [13]. While FFS OBA data have merit for data exploration and analysis purposes, their limitations (and those of similar fire records based on point locations) must be recognized. The geospatial accuracy (i.e., the co-occurrence of the burn and the point provided) of the data points was found to vary substantially across the state and over time. In addition, the database provides point locations only and lacks a standardized mechanism to track the completed extent of burns. These factors can all contribute to the mischaracterization of burning when relying on the FFS OBA alone. The lack of spatial information indicating areas burned in OBA records especially limits its use for conservation planning and prescribed fire prioritization. In addition to the FFS OBA data, many other public agencies are required to document wildfire and prescribed fire perimeters for reporting purposes on agency-owned land. The goals and purpose of fire reporting vary across agencies, and consequently, there is currently no cross-dataset standardization meaning the tracking, mapping, attributing, and reporting methods vary among and within ownerships, as shown in Figure 1. Even though the agency-provided fire information included perimeters of burn units and sometimes burnable areas, the agency-provided data still lacked the spatial detail needed to generate fire histories, assess fire impacts, and prioritize areas for future prescribed fire across the state as a whole.

Despite the inconsistencies, prescribed and wildfire perimeters and fire occurrence data do have utility as ancillary or supplemental information sources when comparing with satellite-based data sources, especially in identifying areas where and when fire was applied to the land, irrespective of how the effects appear in satellite datasets. The absence of fire perimeters in the FFS OBA dataset and the lack of records for private lands necessitated the use of the Landsat BA products, which we found to generally represent landscape burn patterns well across the state. While we recognize that the dataset does not encompass all fires, nor does it always capture all of the area burned within a given fire, it does hold promise for mapping fire spatial extents in locations where fire sizes are small and where spatial data tracking data do not currently exist-particularly on private lands. For example, the BA products provide information that was previously lacking on the $70 \%$ of Florida lands in private ownership [15]. In a state that reports upwards of 900,000 ha per year of prescribed fire [13], that is a significant improvement in understanding fire occurrence. 


\subsection{Challenges and Limitations of 90BP Fire Metrics}

Detecting burned area across the SE using multispectral satellites, however, faces many challenges. Fires across the SE tend to be small in area; post-fire green-up can be rapid yielding a 'missed' fire detection; cloud cover and shadows obscuring burn signatures are common during summer months; satellites are unable to distinguish between prescribed and numerous small wildfires; low-intensity burn signatures are obscured beneath tree canopies; daily overpasses may not detect heat due to timing of overpass versus burn; and the satellite product resolution is often too coarse to capture fine-scale differences or small burns [34,58]. Furthermore, exact dates of fires are not discernible unless the fire is active during a satellite overpass. For example, at one pilot location, managers helped us determine that some of the 'unmapped' fires were fires that actually burned with such low intensity that they could not cause an ecological change that would be detected by remote sensing (such as might happen when burning off a thin layer of needles on a sandy substrate or in an area in a maintenance phase as opposed to restoration). Through meetings with managers, we confirmed many explanations as to why no burn was detected and where/why fire detection was performing very well, as well as some suggestions for improvements. For instance, manager feedback suggests that more work needs to be done to understand fire detection in water-dominated ecosystems, such as those found in Big Cypress and the Everglades, that regularly burn by both wildfires and prescribed fires. However, we found that many managers were not concerned about fires that were 'missed' by the BA-based products, and their explanations/comments for these 'unmapped fires' reflect known limitations previously documented [34]. The utility of fire history metrics derived from remotely sensed BA products was recognized by managers when limitations of the underlying 90BP data were well characterized and understood.

Additionally, this project is regionally based, and as such, may not wholly represent fires - especially small fires - with appropriate details at a local level. Consequently, much can still be gained by acquiring local datasets, interviews/meetings with local experts, and integrating independent fire mapping efforts where the regional approach may underrepresent fire events. We found this validation to be important for understanding the BA-based fire rotation values. Statewide values (Table 2) represent area burned and fire rotations for the entire state, as opposed to a specific area of interest such as the Apalachicola National Forest. This difference could make BA-derived values appear unexpectedly high (or low) relative to expected values published in the literature [39,57]. These differences should not immediately be misinterpreted as a habitat type or location not receiving the appropriate amount of fire; rather, it does illustrate the importance of verifying the BA-based results with local land managers and spatial data records. The differences between published and BA-derived values can be attributed to many factors, including a short period of record for this work, varying scales between statewide and focal areas, the definition of fire rotation (vs. average fire frequency), low-intensity burns not triggering detectable differences in satellite imagery, and calculating from a mosaic burn pattern vs. point or polygon-derived datasets.

\subsection{Utility of the Datasets}

Despite the limitations of the Landsat BA product, based on manager feedback, we feel that this effort is worth expanding, specifically by including as much of the Landsat archive as possible to generate BA products and capture information on ecosystems with fire rotations longer than 10 years. This effort, therefore, should be considered a starting point for managers and researchers to work together to evaluate the process, methodology, and fire products at a state or subregional level in order to develop tools and products that will be helpful in the future (sensu $[37,56])$. A comprehensive validation study is needed to evaluate these products, and a process with which to incorporate updates and suggestions for improvement of burn mapping protocols would be of value given the fragmented nature of prescribed fire spatial data. However, such quantitative validation of the fire history metrics is not yet possible because of the shortcomings in existing datasets 
we described here and the limited temporal coverage of reference data used in previous validation efforts $[35,36,59]$.

The data derivations produced in this study are standardized and replicable across landscapes and do not require a priori knowledge of fires to be generated. They provide spatial information that is potentially more useful than either a point-based dataset or a burn unit dataset alone. Because of the longevity of many of the current satellite sensors and products that we evaluated, scientific literature describing the known limitations, assumptions, and utility of different algorithms and datasets for fire detections and burn scar mapping in various ecosystems is abundant. Therefore, hosting manager evaluation meetings is important when developing and producing these products to discuss the pros and cons and understand where the products are performing well and where they need improvements. Overall, the Landsat BA-based datasets and their derivatives show promise to extract fire extent information across large regional areas in a standardized replicable way, which makes it possible to process data from sensors in a consistent manner for comparing to known fire locations, as well as capturing burned areas that are currently missing from many records. The spatial and temporal consistency of the Landsat BA data is what makes them ideal for generating fire history metrics that can be used to inform decision making by land and fire managers.

\section{Conclusions}

This project is a first step at mapping fire spatial extent and employed coproduction for stakeholder-driven science participation [56]. While there is still a gap between the scientific products being produced and the regional and national data needs for answering management-driven and science-driven questions, the results of this work are promising. Wall-to-wall fire extents across all ownerships have not been mapped previously for Florida (or any state, for that matter) or at these scales (e.g., less than the 202 ha MTBS fires). Our work highlights the national BA dataset that is produced with standardized and replicated methods: we found that the BA products can be leveraged to derive critical fire history metrics across landscapes, which provide actionable management-relevant information. These datasets and information can be readily ingested for management use, such as setting regional conservation priorities for fire-adapted species (sensu [1]). Moreover, they can be used by researchers, scientists, and policymakers at regional to national scales to address fuel treatment patterns and priorities. Further refinements to improve the utility of the products should be evaluated moving forward, as new remote sensing platforms, algorithms, and updates to fire records occur. It is our hope that with these BA-based datasets, we can document where spatial and temporal patterns are changing and assess how managed fire regimes meet conservation or risk management objectives at a variety of scales.

Supplementary Materials: The Landsat Burned Area products are available for download from U.S. Geological Survey's ScienceBase Catalog (https: / / doi.org/10.5066/P9QKHKTQ; accessed on 1 February 2021 [43]). Statewide BA-based products generated for Florida are available for download from the Florida Fish and Wildlife Conservation Commission [60].

Author Contributions: Conceptualization, J.N., C.T. and J.K.H.; methodology, C.T. and J.N.; investigation, C.T., T.J.H. and M.K.V.; formal analysis, C.T., T.J.H. and M.K.V.; resources, J.N., T.J.H. and M.K.V.; data curation, J.N., T.J.H. and M.K.V.; writing-original draft preparation, C.T.; writingreview and editing, C.T., J.N., T.J.H., M.K.V. and J.K.H.; project administration, J.N.; funding acquisition, J.N. and J.K.H. All authors have read and agreed to the published version of the manuscript.

Funding: This research was funded by the Florida Fish and Wildlife Conservation Commission's program, Florida's Wildlife Legacy Initiative, and the US Fish and Wildlife Service's State Wildlife Grants Program (FL-T-F18AF00493; Federal Award Name: T-50 Freshwater, Data Gaps, and Terrestrial Projects, Grant Cycle 2017; FWC Agreement No. 18003). We would also like to acknowledge the U.S. Geological Survey's Core Science Systems Mission Area that provided funding for Todd Hawbaker 
and Melanie Vanderhoof through the National Land Imaging Program and Land Chance Science Program to assist with processing the burned area products for Florida.

Acknowledgments: We would like to acknowledge the support provided for the project by Vince Sclafani and Dixie Davis who provided database and scripting assistance. Additionally, we thank all the agencies, staff, and landowners that contributed data for this effort including Florida Forest Service; USFS Forests in Florida; Florida Park Service; U.S. National Park Service; U.S. Air Force Wildland Fire Center/Jackson Guard; U.S. National Wildlife Refuges; Tall Timbers Research Station; Archbold Research Station; and The Nature Conservancy. Finally, we would like to thank Janet Slate, Harland Goldstein, Josh Picotte, and Inga La Puma for reviewing earlier drafts of the manuscript, and Jeremy Havens for support with graphics.

Conflicts of Interest: The authors declare no conflict of interest. The funders had no role in the design of the study; in the collection, analyses, or interpretation of data; in the writing of the manuscript, or in the decision to publish the results. Any use of trade, product, or firm names is for descriptive purposes only and does not imply endorsement by the U.S. Government.

\section{References}

1. Hiers, J.K.; Laine, S.C.; Bachant, J.J.; Furman, J.H.; Greene, W.W.; Compton, V. Simple Spatial Modeling Tool for Prioritizing Prescribed Burning Activities at the Landscape Scale. Conserv. Biol. 2003, 17, 1571-1578. [CrossRef]

2. Collins, B.M.; Das, A.J.; Battles, J.J.; Fry, D.L.; Krasnow, K.D.; Stephens, S.L. Beyond Reducing Fire Hazard: Fuel Treatment Impacts on Overstory Tree Survival. Ecol. Appl. 2014, 24, 1879-1886. [CrossRef] [PubMed]

3. Hahn, G.E.; Coates, A.T.; Latham, R.E.; Majidzadeh, H. Prescribed Fire Effects on Water Quality and Freshwater Ecosystems in Moist-Temperate Eastern North America. Nat. Areas J. 2019, 39, 46-57. [CrossRef]

4. Kolden, C.A. We're Not Doing Enough Prescribed Fire in the Western United States to Mitigate Wildfire Risk. Fire 2019, 2, 30. [CrossRef]

5. North, M.P.; Stephens, S.L.; Collins, B.M.; Agee, J.K.; Aplet, G.; Franklin, J.F.; Fule, P.Z. Reform Forest Fire Management. Science 2015, 349, 1280-1281. [CrossRef] [PubMed]

6. Ryan, K.C.; Knapp, E.E.; Varner, J.M. Prescribed Fire in North American Forests and Woodlands: History, Current Practice, and Challenges. Front. Ecol. Environ. 2013, 11, e15-e24. [CrossRef]

7. Crowder, L. Prescribed Fire Gains Momentum. Calif. Agric. 2019, 73, 5-8. [CrossRef]

8. United States Forest Service (USFS) Memorandum of Understanding for the Purpose of Increasing the Use of Fire to Meet Ecological and Other Management Objectives. Available online: https://www.sierraforestlegacy.org/Resources/Community/ PrescribedFire/FireMOUSigned.pdf (accessed on 1 January 2021).

9. Liu, Y.; Prestemon, J.P.; Goodrick, S.L.; Holmes, T.P.; Stanturf, J.A.; Vose, J.M.; Sun, G. Future Wildfire Trends, Impacts, and Mitigation Options in the Southern United States. In Climate Change Adaption and Mitigation Management Options: A Guide for Natural Resource Managers in Southern Forest Ecosystems; CRC Press: Boca Raton, FL, USA; Taylor and Francis: Boca Raton, FL, USA, 2014; pp. 85-126.

10. Waldrop, T.A.; Goodrick, S.L. Introduction to Prescribed Fires in Southern Ecosystems: Science Update SRS-054. 2018 ; p. 80. Available online: https:/ /www.fs.usda.gov/treesearch/pubs/41316 (accessed on 2 April 2019).

11. Melvin, M.A. 2015 National Prescribed Fire Use Survey Report; National Association of State Foresters: Washington, DC, USA; Coalition of Prescribed Fire Councils: Newton, GA, USA, 2015; p. 22. Available online: http://www.stateforesters.org/2015 -national-prescribed-fire-use-survey-report (accessed on 1 April 2019).

12. Wildland Fire Annual Reports. Available online: https://www.predictiveservices.nifc.gov/intelligence/2018_statssumm/ annual_report_2018.pdf (accessed on 15 May 2019).

13. Nowell, H.K.; Holmes, C.D.; Robertson, K.; Teske, C.C.; Hiers, J.K. A New Picture of Fire Extent, Variability, and Drought Interaction in Prescribed Fire Landscapes: Insights from Florida Government Records. Geophys. Res. Lett. 2018, 45, 7874-7884. [CrossRef]

14. Addington, R.N.; Hudson, S.J.; Hiers, J.K.; Hurteau, M.D.; Hutcherson, T.F.; Matusick, G.; Parker, J.M. Relationships among Wildfire, Prescribed Fire, and Drought in a Fire-Prone Landscape in the South-Eastern United States. Int. J. Wildland Fire 2015, 24, 778-783. [CrossRef]

15. Florida Natural Areas Inventory: Florida Conservation Lands. Available online: https://www.fnai.org/gisdata.cfm (accessed on 2 April 2019).

16. Steen, D.A.; Conner, L.M.; Smith, L.L.; Provencher, L.; Hiers, J.K.; Pokswinski, S.; Helms, B.S.; Guyer, C. Bird Assemblage Response to Restoration of Fire-Suppressed Longleaf Pine Sandhills. Ecol. Appl. 2013, 23, 134-147. [CrossRef]

17. Steen, D.A.; Smith, L.L.; Conner, L.M.; Litt, A.R.; Provencher, L.; Hiers, J.K.; Pokswinski, S.; Guyer, C. Reptile Assemblage Response to Restoration of Fire-Suppressed Longleaf Pine Sandhills. Ecol. Appl. 2013, 23, 148-158. [CrossRef]

18. Myers, R.L.; Ewel, J.J. Ecosystems of Florida; University Press of Florida: Gainesville, FL, USA, 1990; ISBN 978-0-8130-1012-0.

19. Hiers, J.K.; Mitchell, R.J.; Barnett, A.; Walters, J.R.; Mack, M.; Williams, B.; Sutter, R. The Dynamic Reference Concept: Measuring Restoration Success in a Rapidly Changing No-Analogue Future. Ecol. Restor. 2012, 30, 27-36. [CrossRef] 
20. Trager, M.D.; Drake, J.B.; Jenkins, A.M.; Petrick, C.J. Mapping and Modeling Ecological Conditions of Longleaf Pine Habitats in the Apalachicola National Forest. J. For. 2018, 116, 304-311. [CrossRef]

21. Glitzenstein, J.S.; Streng, D.R.; Wade, D.D. Fire Frequency Effects on Longleaf Pine (Pinus Palustris P. Miller) Vegetation in South Carolina and Northeast Florida, USA. Nat. Areas J. 2003, 23, 22-37.

22. Kirkman, L.K.; Goebel, P.C.; Palik, B.J.; West, L.T. Predicting Plant Species Diversity in a Longleaf Pine Landscape. Ecoscience 2004, 11, 80-93. [CrossRef]

23. Bowman, D.M.J.S.; Williamson, G.J.; Abatzoglou, J.T.; Kolden, C.A.; Cochrane, M.A.; Smith, A.M.S. Human Exposure and Sensitivity to Globally Extreme Wildfire Events. Nat. Ecol. Evol. 2017, 1, 0058. [CrossRef] [PubMed]

24. Cox, J.; Robertson, K.M.; Masters, R.E.; Reckford, A. Monitoring Prescribed Burning on Public Lands in Florida: Final Report to Florida Fish and Wildlife Conservation Commission State Wildlife Grants Program; Project SWG04-020; Tall Timbers Research Station: Tallahassee, FL, USA, 2006. Available online: https:/ / public.myfwc.com/CrossDOI/fundedprojects/GrantDetails.aspx?ID=27 (accessed on 3 April 2019).

25. Eidenshink, J.; Schwind, B.; Brewer, K.; Zhu, Z.-L.; Quayle, B.; Howard, S.M. A Project for Monitoring Trends in Burn Severity. Fire Ecol. 2007, 3, 3-21. [CrossRef]

26. Finco, M.; Quayle, B.; Zhang, Y.; Lecker, J.; Megown, K.A.; Brewer, K. Monitoring Trends in Burn Severity (MTBS): Monitoring Wildfire Activity for the Past Quarter Century Using Landsat Data. In Moving from Status to Trends: Forest Inventory and Analysis (FIA) Symposium 2012, Baltimore, MD; Gen. Tech. Rep. NRS-P-105; U.S. Department of Agriculture, Northern Research Station: Newtown Square, PA, USA, 2012; pp. 222-228.

27. Liu, Y.; Achtemeier, G.L.; Goodrick, S.L.; Jackson, W.A. Important Parameters for Smoke Plume Rise Simulations with Daysmoke. Atmos. Pollut. Res. 2010, 1, 250-259. [CrossRef]

28. Rollins, M.G. LANDFIRE: A Nationally Consistent Vegetation, Wildland Fire and Fuel Assessment. Int. J. Wildland Fire 2009, 18, 235-249. [CrossRef]

29. Hudak, A.; Robichaud, P.; Evans, J.; Clark, J.; Lannom, K.; Morgan, P.; Stone, C. Field Validation of Burned Area Reflectance Classification (BARC) Products for Post Fire Assessment. 2004. Available online: https://digitalcommons.unl.edu/usdafsfacpub/ 220 (accessed on 3 April 2019).

30. French, N.H.; McKenzie, D.; Erickson, T.; Koziol, B.; Billmire, M.; Endsley, K.; Scheinerman, N.K.Y.; Jenkins, L.; Miller, M.E.; Ottmar, R.; et al. Modeling Regional-Scale Wildland Fire Emissions with the Wildland Fire Emissions Information System. Earth Interact 2014, 18, 1-26. [CrossRef]

31. Urbanski, S.P.; Reeves, M.C.; Corley, R.E.; Silverstein, R.P.; Hao, W.M. Contiguous United States Wildland Fire Emission Estimates during 2003-2015. Earth Syst. Sci. Data 2018, 10, 2241-2274. [CrossRef]

32. Hawbaker, T.J.; Vanderhoof, M.K.; Schmidt, G.L.; Beal, Y.J.; Picotte, J.J.; Takacs, J.D.; Falgout, J.T.; Dwyer, J.L. The Landsat Burned Area Algorithm and Products for the Conterminous United States. Remote Sens. Environ. 2020, 244, 111801. [CrossRef]

33. Hawbaker, T.J.; Vanderhoof, M.K.; Beal, Y.J.; Takacs, J.D.; Schmidt, G.L.; Falgout, J.T.; Williams, B.; Brunner, N.M.; Caldwell, M.K.; Picotte, J.J.; et al. Landsat Burned Area Essential Climate Variable Products for the Conterminous United States (1984-2015) (Ver. 1.1, September 2017): U.S. Geological Survey Data Release. Available online: https:/ / doi.org/10.5066/F73B5X76 (accessed on 31 January 2021).

34. Hawbaker, T.J.; Vanderhoof, M.K.; Takacs, J.D.; Schmidt, G.L.; Falgout, J.T.; Williams, B.; Fairaux, N.M.; Caldwell, M.K.; Picotte, J.J.; Howard, S.M.; et al. Mapping Burned Areas Using Dense Time-Series of Landsat Data. Remote Sens. Environ. 2017, 504-522. [CrossRef]

35. Vanderhoof, M.K.; Brunner, N.M.; Beal, Y.J.; Hawbaker, T.J. Evaluation of the U.S. Geological Survey Landsat Burned Area Essential Climate Variable Across the Conterminous U.S. Using Commercial High-Resolution Imagery. Remote Sens. 2017, 9, 743. [CrossRef]

36. Vanderhoof, M.K.; Fairaux, N.M.; Beal, Y.J.; Hawbaker, T.J. Validation of the USGS Landsat Burned Area Essential Climate Variable (BAECV) across the Conterminous United States. Remote Sens. Environ. 2017, 198, 393-406. [CrossRef]

37. Cravens, A.E. How and Why Upper Colorado River Basin Land, Water, and Fire Managers Choose to Use Drought Tools (or Not); U.S. Geological Survey Open-File Report 2018-1173; U.S. Geological Survey: Reston, VA, USA, 2018; 60p. [CrossRef]

38. United States Climate Data (USCD) US Climate Data: Florida. Available online: https://www.usclimatedata.com/climate/ florida/united-states/3179 (accessed on 1 November 2018).

39. Sadler, J.; Brenner, J.; Wade, D.; Schortemeyer, J.L.; Dye, R.; Proctor, T.; Rittenberry, D.; Myers, R.; Coulliette, B. Florida Certified Prescribed Burn Manager Training Course Manual. 2014. Available online: https:/ /www.fdacs.gov/Forest-Wildfire/WildlandFire/Prescribed-Fire/Certified-Prescribed-Fire-Acreage (accessed on 10 April 2021).

40. Barrett, S.; Havlina, D.; Jones, J.; Hann, W.; Frame, C.; Hamilton, D.; Schon, K.; Demeo, T.; Hutter, L.; Menakis, J. Interagency Fire Regime Condition Class Guidebook. Version 3.0. Available online: https:/ / www.landfire.gov/frcc/frcc_guidebooks.php (accessed on 1 December 2020).

41. Short, K.C. Spatial Wildfire Occurrence Data for the United States, 1992-2015. Available online: https://www.fs.usda.gov/rds / archive/Catalog/RDS-2013-0009.4/ (accessed on 15 March 2018).

42. Huang, R.; Zhang, X.; Chan, D.; Kondragunta, S.; Russell, A.G.; Odman, M.T. Burned Area Comparisons Between Prescribed Burning Permits in Southeastern United States and Two Satellite-Derived Products. J. Geophys. Res. Atmos. 2018, 123, $4746-4757$. [CrossRef] 
43. Hawbaker, T.J.; Vanderhoof, M.K.; Schmidt, G.L.; Beal, Y.; Picotte, J.J.; Takacs, J.D.; Falgout, J.T.; Dwyer, J.L. Landsat Burned Area Essential Climate Variable Products for the Conterminous United States: U.S. Geological Survey Data Release. Available online: https: / / doi.org/10.5066/P9QKHKTQ (accessed on 31 January 2021).

44. Agee, J.K. Fire Ecology of Pacific Northwest Forests; Island Press: Washington, DC, USA, 1996; ISBN 978-1-55963-230-0.

45. Sommers, W.T.; Coloff, S.G.; Conard, S.G. Fire History and Climate Change: Project 09-2-01-09. 2011; p. 215. Available online: https://www.firescience.gov/projects /09-2-01-9/project/09-2-01-9_Final_Report_JFSP_09-2-01-09_Fire_History_and_ Climate_Change_by_Chapter_111013.pdf (accessed on 3 April 2018).

46. Teske, C.C.; Seielstad, C.A.; Queen, L.P. Characterizing Fire-on-Fire Interactions in Three Large Wilderness Areas. Fire Ecol. 2012, 8, 82-106. [CrossRef]

47. Anderson, J.; (U.S. Forest Service, Tallahassee, FL, USA). Personal Communication, 2018.

48. Clark, K.L.; Skowronski, N.; Gallagher, M.; Renninger, H.; Schafer, K. Effects of Invasive Insects and Fire on Forest Energy Exchange and Evapotranspiration in the New Jersey Pinelands. Agric. For. Meteorol. 2012, 166-167, 50-61. [CrossRef]

49. Baker, W.A. Fire Ecology in Rocky Mountain Landscapes; Island Press: Washington, DC, USA, 2009; ISBN 978-1-59726-183-8.

50. Florida's Wildlife Legacy Initiative: Florida's State Wildlife Action Plan. Available online: https://myfwc.com/conservation/ special-initiatives/fwli/action-plan/ (accessed on 1 June 2017).

51. Florida Fish and Wildlife Conservation Commission (FWC) GIS \& Mapping Data Downloads: Florida Cooperative Land Cover. Available online: https:/ / geodata.myfwc.com/datasets/f7bb9259f6c7462d8de73b90169eaf43 (accessed on 1 March 2021).

52. Komarek, E.V. The Meteorological Basis for Fire Ecology. In Proceedings of the Fifth Annual Tall Timbers Fire Ecology Conference, Tallahassee, FL, USA, 24-25 March 1966; pp. 85-126. Available online: https://talltimbers.org/wp-content/uploads/2018/09/85 -KomarekEV1966_op.pdf (accessed on 1 March 2018).

53. Komarek, E.V. The Nature of Lightning Fires. In Proceedings of the California [7th] Tall Timbers Fire Ecology Conference, Hoberg, CA, USA, 9-10 November 1967; Tall Timbers Research Station: Tallahassee, FL, USA, 1968; pp. 5-41. Available online: https://talltimbers.org/wp-content/uploads/2018/09/5-Komarek1967_op-1.pdf (accessed on 1 March 2018).

54. Wiens, J.; Sutter, R.; Anderson, M.; Blanchard, J.; Barnett, A.; Aguilar-Amuchastegui, N.; Avery, C.; Laine, S.C. Selecting and Conserving Lands for Biodiversity: The Role of Remote Sensing. Remote Sens. Environ. 2009, 113, 1370-1381. [CrossRef]

55. Kupfer, J.A.; Terando, A.J.; Gao, P.; Teske, C.C.; Hiers, J.K. Climate Change Projected to Reduce Prescribed Burning Opportunities in the South-Eastern United States. Int. J. Wildland Fire 2020, 29, 764-778. [CrossRef]

56. Enquist, C.A.; Jackson, S.T.; Garfin, G.M.; Davis, F.W.; Gerber, L.R.; Littell, J.A.; Tank, J.L.; Terando, A.J.; Wall, T.U.; Halpern, B.; et al. Foundations of Translational Ecology. Front. Ecol. Environ. 2017, 15, 541-550. [CrossRef]

57. Florida Natural Areas Inventory (FNAI). Guide to the Natural Communities of Florida: 2010, 2010 ed.; Florida Natural Areas Inventory: Tallahassee, FL, USA, 2010.

58. Hawbaker, T.J.; Radeloff, V.C.; Syphard, A.D.; Zhu, Z.; Stewart, S.I. Detection Rates of the MODIS Active Fire Product in the United States. Remote Sens. Environ. 2008, 112, 2656-2664. [CrossRef]

59. Franquesa, M.; Vanderhoof, M.K.; Stavrakoudis, D.; Gitas, I.Z.; Roteta, E.; Padilla, M.; Chuvieco, E. Development of a Standard Database of Reference Sites for Validating Global Burned Area Products. Earth Syst. Sci. Data 2020, 12, 3229-3246. [CrossRef]

60. Florida Fish and Wildlife Conservation Commission (FWC) Florida Fire Occurrence Dataset. Available online: https: / / myfwc. $\mathrm{com} /$ research/gis/regional-projects/florida-fire/ (accessed on 10 April 2021). 